\title{
Impact of photoperiodic exposures during late gestation and lactation periods on the pineal and reproductive physiology of the Indian palm squirrel, Funambulus pennanti
}

\author{
K. S. Bishnupuri and C. Haldar \\ Department of Zoology, Banaras Hindu University, Varanasi-221 005, India
}

\begin{abstract}
Studies on the maternal transfer of photoperiodic information in mammals indicate that the daily photoperiod perceived by the mother during the gestation-lactation period is communicated to the fetus either through the placenta or via the milk. However, the impact of photoperiodic exposures during gestation and lactation on the maternal pineal and reproductive physiology has not been reported for any tropical rodent. The exposure of pregnant female Indian palm squirrels (Funambulus pennanti) to constant light ( $24 \mathrm{~h}$ light: $0 \mathrm{~h}$ dark), constant dark ( $0 \mathrm{~h}$ light: $24 \mathrm{~h}$ dark), long daylength (14 h light: $10 \mathrm{~h}$ dark) or short daylength ( $10 \mathrm{~h}$ light: $14 \mathrm{~h}$ dark) during early gestation (<30 days) resulted in the resorption of pregnancy, while during late gestation ( $>30$ days), it did not interfere with the maintenance of pregnancy. Alterations in photoperiodic condition during late gestation and lactation altered the postpartum recovery process. Pineal gland activity, as assessed by pineal mass, protein content and plasma melatonin, was lowest during the breeding phase, but increased gradually after parturition until the next breeding phase. During gestation and lactation, constant light, long daylength and short daylength conditions were less effective, while constant dark condition had a profound effect in depressing pineal gland activity, which subsequently advanced postpartum recovery. Hence, lactating females under constant darkness prepare themselves for next mating much earlier than females under natural daylength $(12 \mathrm{~h}$ light:12 h dark) conditions. Therefore, photoperiodic information, mediated via the pineal gland, may be important for maintaining gestation physiology as well as postpartum recovery in female rodents.
\end{abstract}

\section{Introduction}

Mammals exhibit an intricate interplay of hormonal events in their reproductive functions that regulates the development and maturation of gametes in addition to the major events of the oestrous cycle (ovulation and sexual receptivity) and the preparation of the uterus for the possible implantation of the embryo. In most species in the wild, these processes are restricted to a specific time of the year. During the course of evolution, there has been selection against animals whose offspring are born when the conditions for survival are not optimal (Cardinali and Vacas, 1984). The major environmental variable controlling seasonal reproductive activity is photoperiod (Elliot, 1976; Stetson and Tate-Ostroff, 1981).

Mammals in the temperate zone often breed seasonally and this seasonality is usually enforced by a dependence on

Revised manuscript received 17 August 1999. daylength. Information about the daily photoperiod passes from the retina to the suprachiasmatic nucleus (SCN) and the superior cervical ganglion (SCG) to the pineal gland, where melatonin is secreted at night (Reiter, 1991). Studies in several species show that the sympathetic nervous system is responsible for the control of the circadian variation in pineal melatonin secretion and that the suprachiasmatic nuclei are essential components of the photoperiodic mechanisms participating in the generation of circadian rhythms, including the rhythms in photosensitivity (Bowers and Zigmond, 1982; Reiter 1984).

The daily duration of the increase in melatonin secretion regulates the secretion of gonadotrophin (Tamarkin et al., 1985; Reiter, 1986; Binkley, 1988) and gonadal steroids, which regulates the breeding. The mammalian pineal gland is thought to be involved in reproduction (Carter and Goldman, 1983; Reiter, 1991). In long day breeders, such as ferrets, voles or hamsters, short photoperiod induces gonadal regression, while long photoperiod hastens development or recrudescence. The opposite effect is observed in animals such as sheep, goats and deer, in which gonads mature in autumn or 
winter (Cardinali and Vacas, 1984). It has been claimed that, during long photoperiods, animals are physiologically pinealectomized (Reiter, 1978) and, during short photoperiods, that the pineal is hyperactive.

To date, reports are available only on the impact of photoperiod and the pineal gland on the reproductive system of laboratory mammals. Little is known about the functional activity of photoperiod on the pineal-gonadal axis in tropical female rodents. Most of the work regarding the influence of photoperiod on reproduction has been done on laboratory rodents, such as hamsters or rats. To date, no reports are available on the influence of photoperiod on reproduction in seasonal breeders that inhabit the tropical zone. Therefore, the aim of the present study was to investigate the impact of photoperiodic exposure on the function of the pineal gland and the reproductive activity of the lactating Indian palm squirrel, Funambulus pennanti.

The annual reproductive activity of female Indian palm squirrels has been investigated in the authors' laboratory (Haldar and Singh, 1995). Reproduction in this tropical rodent exhibits a distinct seasonal cyclicity. Indian palm squirrels breed seasonally and, usually, a large number of pregnant females are present in March and April. A smaller number of pregnant females are also found during August and September. The gestation period of Indian palm squirrels varies from 42 to 45 days.

\section{Materials and Methods}

\section{Capture and maintenance of animals}

Sixty pregnant female Indian palm squirrels (body weight: $120 \pm 5 \mathrm{~g}$ ) were collected from the vicinity of Varanasi (latitude $25^{\circ} 18^{\prime} \mathrm{N}$; longitude $83^{\circ} 1^{\prime} \mathrm{E}$ ) during March. All the pregnant females were kept in separate wire net cages $(0.6 \times 0.6 \mathrm{~m} \times 0.75 \mathrm{~m})$ individually in a room fully exposed to ambient conditions of light, temperature and humidity for an overnight acclimatization to the laboratory condition. The animals were provided with water soaked grain (Cicer arietinum) and water ad libitum.

\section{Experimental schedules}

On the basis of the size of the embryos (assessed by external manual examination), the acclimatized females were divided into two categories: $<30$ days $>30$ days pregnant. Females with embryos $<2.30 \mathrm{~cm}$ were placed in the $<30$ days pregnant category; females with embryos $>2.30 \mathrm{~cm}$ were placed in the $>30$ days pregnant categories. The acclimatized females were divided into five groups of equal number $(n=6)$, which were then exposed to different photoperiodic conditions in separate wooden photoperiodic chambers as shown (Table 1 ).

The duration of light and dark periods in the photoperiodic chambers was maintained with an electric switch clock (VEB, Zeitschaltelektronik, Frauenstein, Germany) connected to a cool fluorescent lamp with a light intensity of $400 \mathrm{~lx}$. The photoperiodic chamber for constant dark was connected to a very low intensity red bulb of $0 \mathrm{~W}$, which was used during the cleaning of chamber and to provide the food and water during the dark phase. Under the various photoperiodic conditions, the gravid females either aborted or delivered pups within 12-18 days. After parturition, the females that delivered pups were kept under the same photoperiodic condition for another 60 days until their pups attained adulthood. All experimental females were killed by decapitation at 60 days post partum under their respective photoperiodic conditions. Animals were killed at night (22:00-23:00 h) to obtain peak values of plasma melatonin. The pineal, ovary, uterus and adrenal glands were dissected out and weighed. The pineal gland was collected on ice and then processed for biochemical analyses of protein and cholesterol content. The blood was collected in heparinized tubes and centrifuged for $10 \mathrm{~min}$ at $3000 \mathrm{~g}$ to collect the plasma. The plasma samples of all the experimental animals were stored at $-20^{\circ} \mathrm{C}$ until the hormonal analysis.

Biochemical analysis. The pineal gland was washed in normal saline and then homogenized in a micro glass homogenizer. The protein content was estimated by spectrophotometry using Folin-Ciocalteau reagent and the method of Lowry et al. (1951), and the cholesterol content was estimated using Leibermann-Berchard reagent (LB. regent) and the method of Stadman (1957).

Hormonal analysis. The plasma melatonin content of respective animals was estimated using the radioimmunoassay method of Rollag and Niswender (1976), modified by Attanasio et al. (1985). The plasma concentrations of oestradiol and progesterone were estimated by commercial radioimmunoassay kits: Estradiol $\left({ }^{125} \mathrm{I}\right)$-coated Radioimmunoassy Kit from Orion Diagnostics (Espoo, Finland) and Progesterone ( $\left.{ }^{125} \mathrm{I}\right)$ Radioimmunoassay Kit from Binax (Portland, ME). The intra-assay variation for hormonal assays was determined from the plasma pools of Indian palm squirrels taken during the active (March-April) and inactive (October-December) reproductive phases. All samples were measured in duplicate. The validations of the melatonin radioimmunoassay were reported by Haldar (1996). The validations of the hormonal assays in the present study are given (Table 2). The linearity of the oestradiol radioimmunoassy was tested by diluting four plasma samples 1:5, 1:10, 1:50 and 1:100 with the zero standard. Calculated observed:expected ratios varied from 92.3 to $111.2 \%$ with a mean of $101.8 \%$. Similarly, the linearity of the progesterone radioimmunoassay was tested by diluting six plasma samples 1:2, 1:4, 1:8, 1:16, 1:32 and 1:64 with the zero standard. Calculated observed:expected ratios varied from 89.8 to $119.42 \%$ with a mean of $104 \%$.

\section{Statistical analyses}

One-way ANOVAs and Newman-Keul's multiple range tests were used in the statistical evaluation of the data. The computer program MSTAT was used for the one-way ANOVA. Data were expressed as mean \pm SEM. 
Table 1. Experimental protocol

\begin{tabular}{lccl}
\hline & \multicolumn{2}{c}{ Number of gravid females } & \\
\cline { 2 - 3 } Groups & $>30$ days of gestation & $<30$ days of gestation & \\
\hline I (control) & 6 & 6 & Photoperiodic schedules \\
II & 6 & 6 & Natural daylength (NDL) \\
III & 6 & 6 & Constant light (LL; 24 h light:0 h dark) \\
IV & 6 & 6 & Constant dark (DD; 0 h light:24 h dark) \\
V & 6 & 6 & Long daylength (LDL; 14 h light:10 h dark) \\
\hline
\end{tabular}

Table 2. Hormonal assay validation data

\begin{tabular}{lccl}
\hline & \multicolumn{2}{c}{ Precision } \\
\cline { 2 - 3 } Hormone & Intra-assay CV $(\%)$ & Interassay CV $(\%)$ & Sensitivity \\
\hline Melatonin & 9.0 & 15.0 & $10 \mathrm{pg} \mathrm{ml}^{-1}$ \\
Oestradiol & 5.97 & 8.13 & $0.817 \mathrm{pg} \mathrm{ml}^{-1}$ \\
Progesterone & 7.3 & 8.6 & $0.8 \mathrm{ng} \mathrm{ml}^{-1}$ \\
\hline
\end{tabular}

CV: coefficient of variation

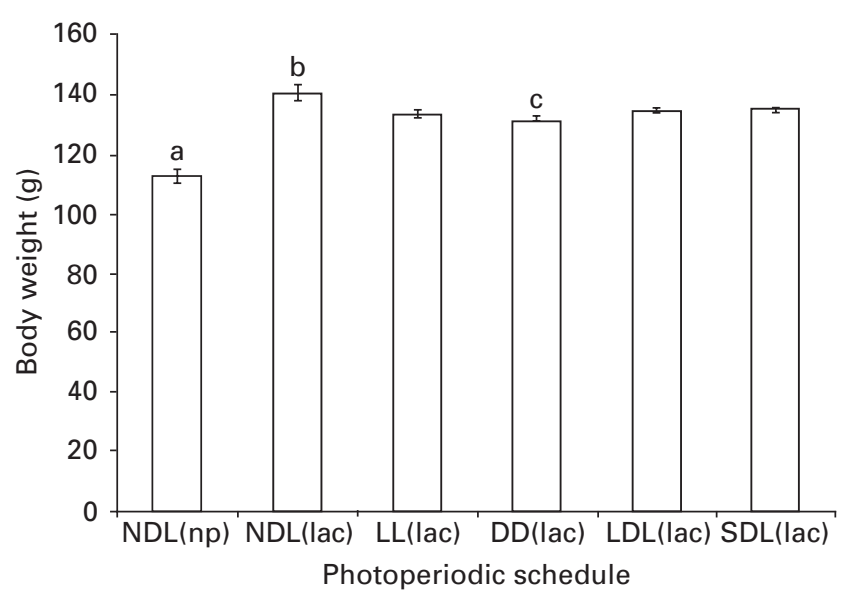

Fig. 1. Effect of natural daylength (NDL), constant light (LL), constant darkness (DD), long daylength (LDL) and short daylength (SDL) on the body weight of lactating (lac) female Indian palm squirrels, Funambulus pennanti (np: non-pregnant). One-way ANOVA: frequency ratio $=19.96, P<0.001$; a compared with $\mathrm{b}: P<$ 0.01 ; b compared with c: $P<0.05$.

\section{Results}

The body weight of the lactating females under natural daylength condition (NDL: $12 \mathrm{~h}$ light:12 h dark) was significantly higher than that of the NDL non-pregnant females. The body weight of lactating females exposed to different photoperiodic conditions tended to be lower than that of NDL lactating females, but this was significant only in the group kept under constant dark (DD) conditions (Fig. 1). Adrenal gland mass was not statistically different in nonpregnant and lactating females under all photoperiodic conditions (Fig. 2).

Ovarian mass decreased significantly after parturition. The ovarian mass of lactating females was significantly higher in females kept under constant light (LL) and DD

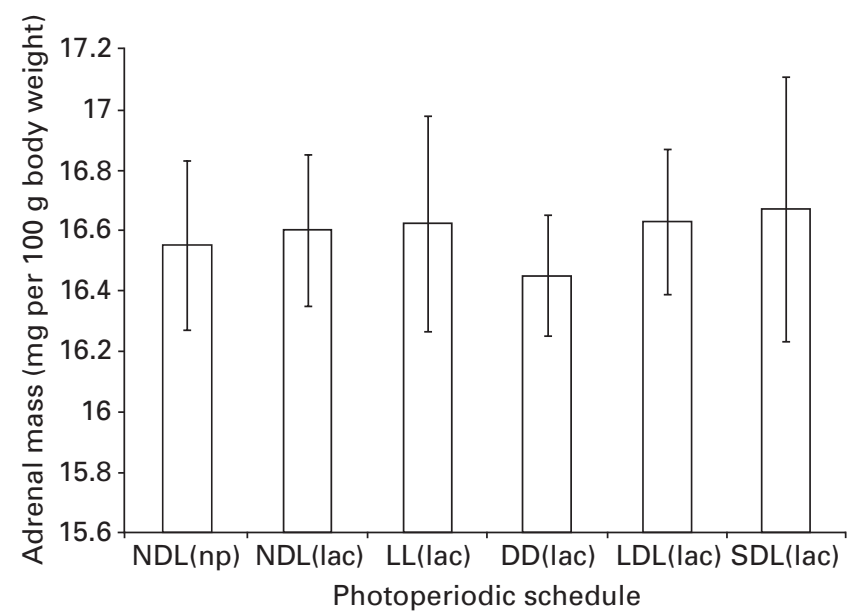

Fig. 2. Effect of natural daylength (NDL), constant light (LL), constant darkness (DD), long daylength (LDL) and short daylength (SDL) on the adrenal gland mass of lactating (lac) female Indian palm squirrels, Funambulus pennanti (np: non-pregnant). One-way ANOVA: frequency ratio $=0.063, P>0.2$.

conditions than in NDL lactating females (Fig. 3). Uterine mass was significantly higher in lactating females than in NDL non-pregnant females. Uterine mass was significantly higher in the LL group and significantly lower in the DD group compared with that of NDL females (Fig. 4).

Pineal gland mass was significantly lower in lactating females than in NDL non-pregnant females and was lower in lactating LL and lactating DD females than in NDL lactating females (Fig. 5). The plasma melatonin content was lower in lactating females than in NDL non-pregnant females. Plasma melatonin concentration was significantly lower in all of the lactating females than in NDL non-pregnant females (Fig. 6). Pineal protein content significantly decreased after parturition and during lactation and was significantly lower in LL and DD females than it was in NDL lactating females (Fig. 7). 


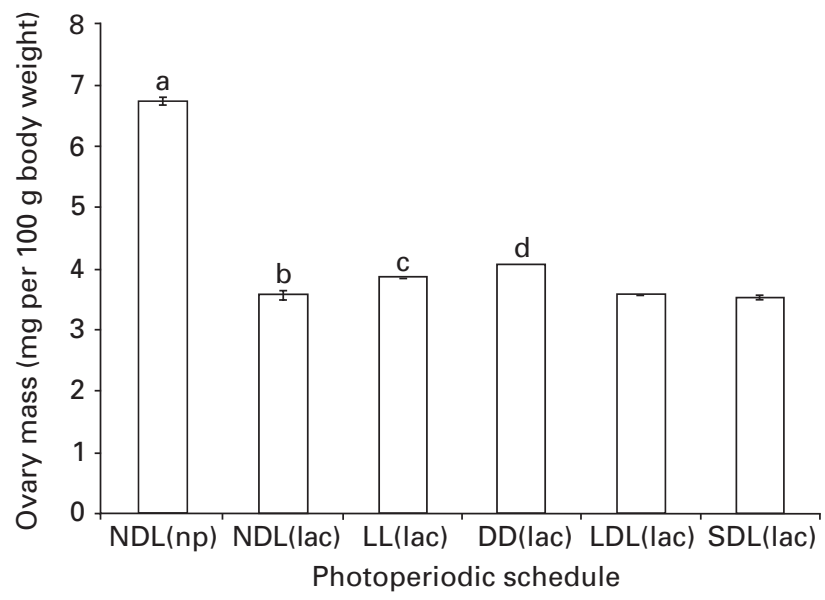

Fig. 3. Effect of natural daylength (NDL), constant light (LL), constant darkness (DD), long daylength (LDL) and short daylength (SDL) on the ovarian mass of lactating (lac) female Indian palm squirrels, Funambulus pennanti (np: non-pregnant). One-way ANOVA: frequency ratio $=306.46, P<0.001$; a compared with $b: P<0.01$; b compared with c: $P<0.05$; b compared with d: $P<0.01$.

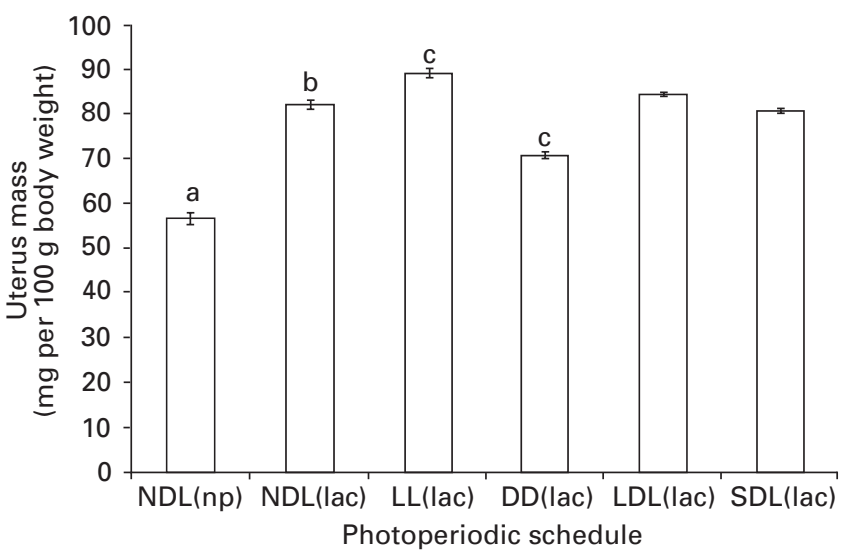

Fig. 4. Effect of natural daylength (NDL), constant light (LL), constant darkness (DD), long daylength (LDL) and short daylength (SDL) on the uterus mass of lactating (lac) female Indian palm squirrels, Funambulus pennanti (np: non-pregnant). One-way ANOVA: frequency ratio $=170.58 ; P<0.001 ;$ a compared with $\mathrm{b}: P<0.01 ; \mathrm{b}$ compared with c: $P<0.01$.

Pineal cholesterol content did not change significantly after parturition or during lactation. There was no significant difference in pineal cholesterol content between females kept under the various photoperiodic conditions and NDL lactating females (Fig. 8).

Plasma oestradiol concentration was significantly higher in lactating females than it was in NDL non-pregnant females. Among lactating females, the plasma oestradiol concentration was similar to that of NDL non-pregnant females. Among lactating females, plasma oestradiol concentration was significantly decreased in LL females and significantly increased in DD females, when compared with NDL lactating females (Fig. 9). The plasma progesterone concentration was significantly lower in the lactating females than in the NDL non-pregnant females. Among lactating

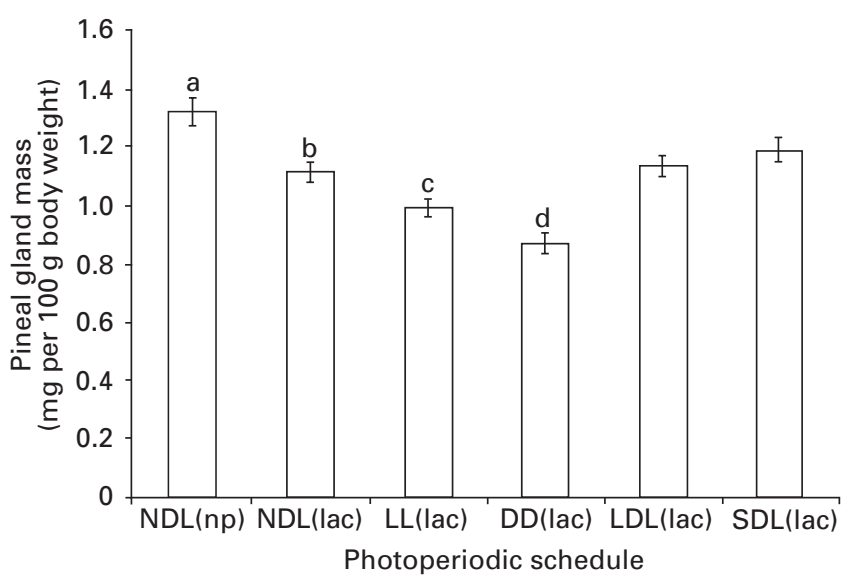

Fig. 5. Effect of natural daylength (NDL), constant light (LL), constant darkness (DD), long daylength (LDL) and short daylength (SDL) on the pineal gland mass of lactating (lac) female Indian palm squirrels, Funambulus pennanti (np: non-pregnant). One-way ANOVA: frequency ratio $=17.33, P<0.001$; a compared with $\mathrm{b}: P<0.01 ; \mathrm{b}$ compared with c: $P<0.05$; c compared with d: $P<0.01$.

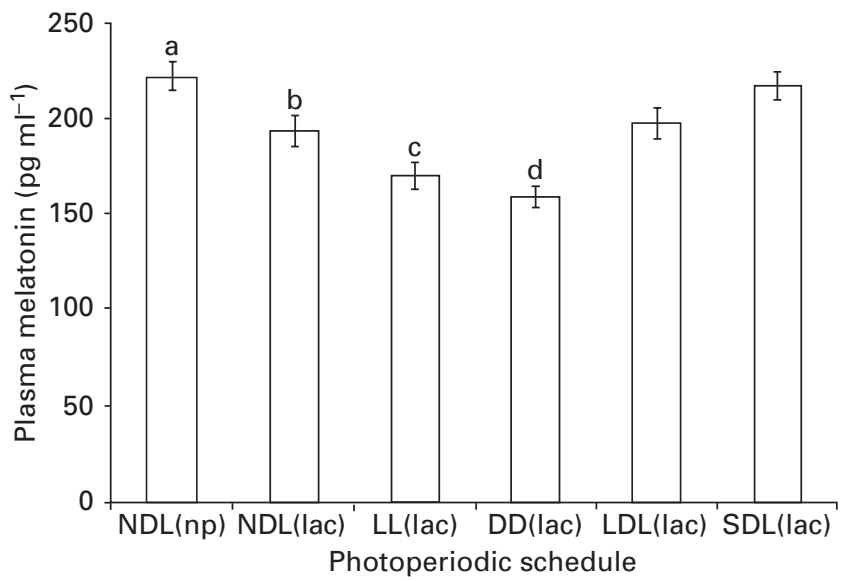

Fig. 6. Effect of natural daylength (NDL), constant light (LL), constant darkness (DD), long daylength (LDL) and short daylength (SDL) on the plasma melatonin concentration of lactating (lac) female Indian palm squirrels, Funambulus pennanti (np: nonpregnant). One-way ANOVA: frequency ratio $=10.93$ and $P<0.001$; a compared with $\mathrm{b}$ : non-significant; $\mathrm{b}$ compared with $\mathrm{c}: P<0.05$; b compared with d: $P<0.01$.

females, the plasma progesterone concentration was significantly lower in the SDL group and significantly higher in the DD group compared with NDL lactating females (Fig. 10).

\section{Discussion}

Melatonin is the means by which the periodicity of the outside world is communicated to the mammalian fetus. In fact, the photoperiodic responses of maternal uterine function may be an adaptation of a physiological mechanism required for fetal development. Stetson et al. (1986) reported 


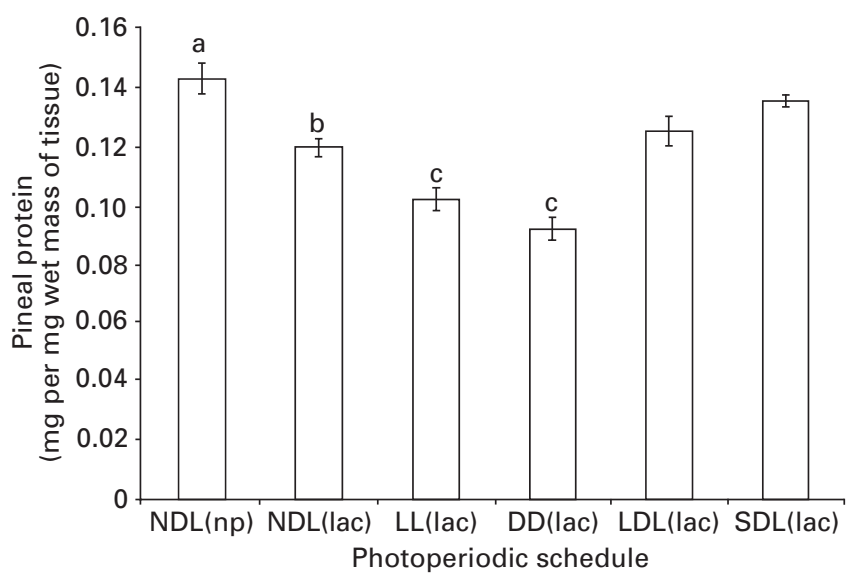

Fig. 7. Effect of natural daylength (NDL), constant light (LL), constant darkness (DD), long daylength (LDL) and short daylength (SDL) on the pineal protein content of lactating (lac) female Indian palm squirrels, Funambulus pennanti (np: non-pregnant). One-way ANOVA: frequency ratio $=18.71, P<0.001$; a compared with $\mathrm{b}$ : $P<0.01$; b compared with c: $P<0.01$.

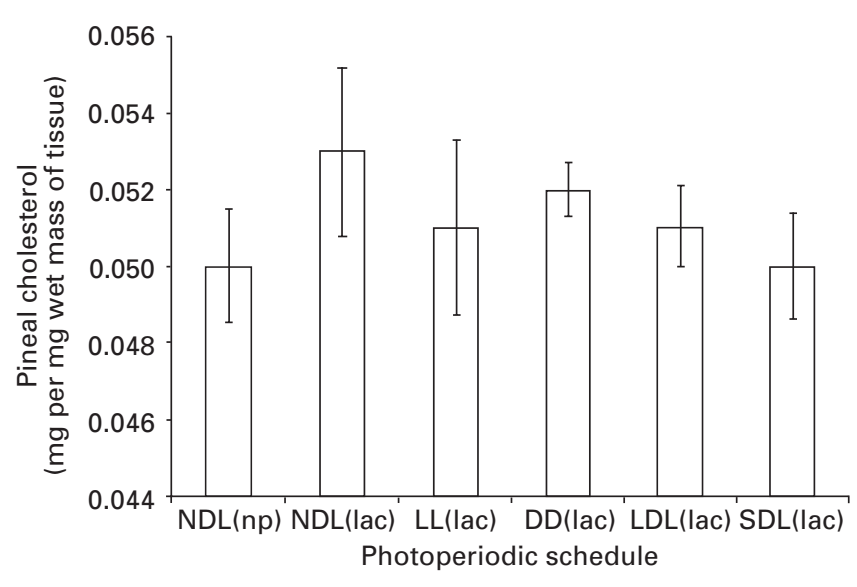

Fig. 8. Effect of natural daylength (NDL), constant light (LL), constant darkness (DD), long daylength (LDL) and short daylength (SDL) on the pineal cholesterol content of lactating (lac) female Indian palm squirrels, Funambulus pennanti (np: non-pregnant). Oneway ANOVA: frequency ratio $=1.90, P<0.2$.

that the information about the photoperiod to which mothers are exposed during gestation is communicated to the fetus. Hence, there may be a direct influence of the maternal pineal gland on the growth and sexual development of growing pups. Furthermore, pregnant and lactating females exposed to different photoperiods undergo physiological changes related to their pineal and reproductive activity.

In the present study, pregnant Indian palm squirrels of $<30$ days gestation resorbed or aborted their embryos when exposed to different photoperiodic conditions (that is, constant light, constant dark, long daylength and short day length) but females of $>30$ days gestation delivered normal

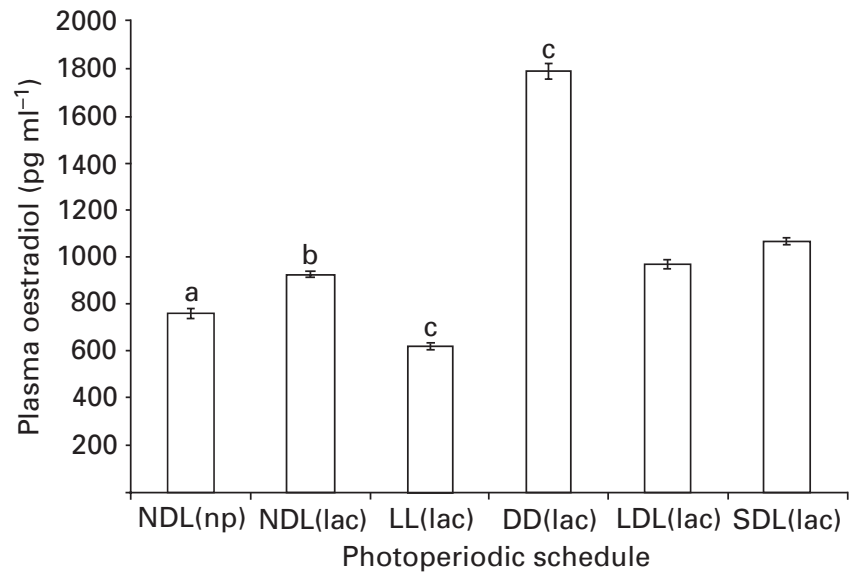

Fig. 9. Effect of natural daylength (NDL), constant light (LL), constant darkness (DD), long daylength (LDL) and short daylength (SDL) on the plasma oestradiol concentration of lactating (lac) female Indian palm squirrels, Funambulus pennanti (np: nonpregnant). One-way ANOVA: frequency ratio $=3372.91, P<0.001$; a compared with b: $P<0.01$; b compared with c: $P<0.01$.

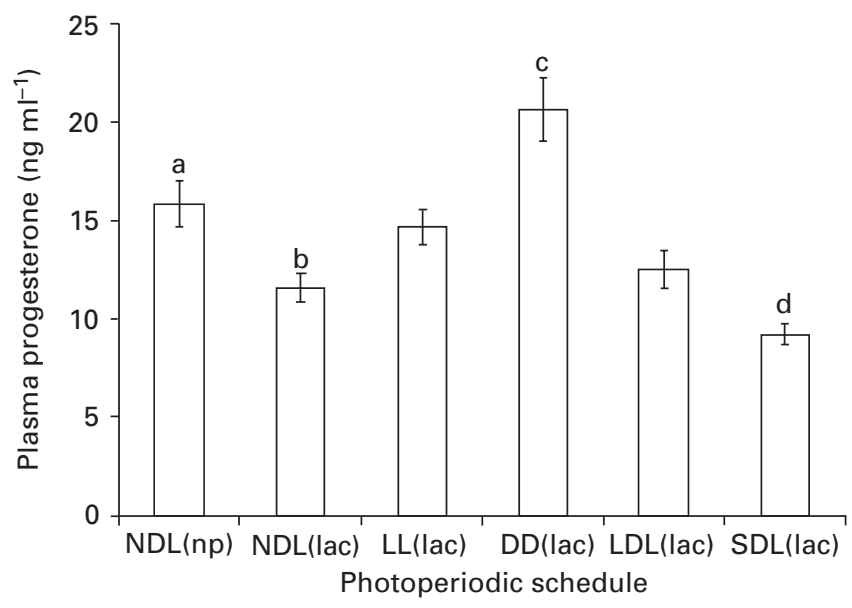

Fig. 10. Effect of natural daylength (NDL), constant light (LL), constant darkness (DD), long daylength (LDL) and short daylength (SDL) on the plasma progesterone concentration of lactating (lac) female Indian palm squirrels, Funambulus pennanti (np: nonpregnant). One-way ANOVA: frequency ratio $=14.47, P<0.001$; a compared with b: $P<0.05$; b compared with c: $P<0.001$; b compared with d: $P<0.05$.

and healthy pups. However, the total gestation period did not vary under the different photoperiodic exposures. Usually, pregnant females of $>30$ days gestation delivered pups between days 42 and 45 of gestation, indicating that there is a critical phase of gestation (at about 30 days) below which the exposure to different photoperiods causes the resorption of the pregnancy. The same changes in photoperiod during late gestation (that is $>30$ days) do not disrupt the ability of females to maintain pregnancy. However, photoperiodic changes during late gestation do alter the growth and sexual development of offspring. 
Horton (1984) described this phenomenon as the maternal transfer of photoperiodic information and viewed it as an adaptive means by which young produce an appropriate response to the change in photoperiod (Horton 1984; Horton et al., 1989, 1990). In females, the pineal gland is known to inhibit the secretion of prolactin after exposure to various photoperiods (Nowak et al., 1985; Forsberg and Madej, 1990; Murphy et al., 1990). As observed in the present study, maternal plasma progesterone and oestradiol concentrations were affected by changes in photoperiod. Hence, in females of $<30$ days gestation, a change in photoperiod might have disrupted the maternal secretion of prolactin, progesterone and oestradiol, resulting in major changes in the maternal ability to maintain uterine function and causing absorption of the fetuses. Later in pregnancy, the placenta may support the uterus to the extent that photoperiodic effects on the anterior pituitary and the ovary are inconsequential. Exposure to different photoperiods may disrupt the endogenous melatonin rhythm of the mother, as reported by Davis (1997).

The body weight of lactating females decreased under every photoperiodic condition other than natural daylength, possibly due to the photoperiodic stress. However, under constant light, long daylength and short daylength conditions, they adapted to the experimental conditions, while constant darkness appeared to generate extreme photoperiodic stress resulting in a significant decrease in body weight. Lactating females were fatter and bulkier under natural daylength, constant light, long daylength and short daylength conditions than they were under constant darkness. Females exposed to constant darkness had less fat deposition in the lower abdominal area. Innes and Miller (1981) suggested that the fat accumulated by females during gestation is metabolized during lactation to fulfil the energetic demand of milk secretion. If this is correct, then, in females experiencing constant darkness, the fat may have been more heavily utilized for milk secretion and better nourishment of pups, reducing their body weight significantly. Females kept under constant dark conditions were healthy despite the low fat deposition in the lower abdominal area (Bishnupuri, 1999) and their pups registered better growth and sexual development (Bishnupuri and Haldar, 1999), ruling out the possibility that these animals experienced greater difficulty in finding food and water. There was no change in the sex ratio in pups born to mothers kept under constant daylight compared with that of females kept under natural daylength and the other experimental conditions. The adrenal gland mass was similar in nonpregnant and lactating females under the various photoperiodic conditions, which indicates that none of the animals were experiencing extreme stress condition. The lactating females appeared to acclimatize themselves to prevailing photoperiodic conditions.

In general, after parturition, females undergo a recovery phase in preparation for the next mating and possible implantation of embryos. In Indian palm squirrels, this postpartum recovery begins with (a) a gradual increase in plasma progesterone after its sharp decrease during parturition; (b) a gradual decrease in uterine mass; (c) an increase in ovarian mass after 1 week; (d) a gradual decrease in body weight due to the metabolization of fat in the lower abdominal area; (e) an increase in plasma oestradiol after its gradual decrease after parturition; and (f) an increase in pineal gland activity. In general, female Indian palm squirrels take about 2 months after parturition to recover their sexual activity and for new embryos to be implanted.

In the present study, ovarian mass decreased significantly after the parturition; hence. a low ovarian mass was observed in lactating females. After parturition, ovarian mass increased during postpartum recovery. However, the recovery process was faster under constant darkness; hence, ovarian mass was greater and uterine mass was lower in females kept under constant darkness compared with lactating females kept under the other photoperiodic conditions. There was an increase in uterine mass in lactating females kept under constant light, which may have been due to a delayed recovery process.

Pineal gland mass and pineal protein content were significantly lower in lactating females kept under constant light or constant darkness. The finding that constant darkness reduced pineal gland activity and melatonin synthesis is contrary to the findings of Bowers and Zigmond (1982) and Reiter (1984) who reported that constant darkness activates pineal gland activity and enhances the synthesis and release of melatonin. Exposure of females to long or short daylength did not affect pineal gland mass significantly. Pineal cholesterol content did not differ among females exposed to the different photoperiodic conditions. This finding indicates that pineal protein is more important than pineal cholesterol for pineal gland activity. Plasma melatonin concentrations were significantly lower in lactating females exposed to constant light or constant darkness. This lower plasma melatonin concentration in females exposed to constant light supports the hypothesis that constant light results in a period of physiological pinealectomy. The finding that plasma melatonin remained detectable in females kept under constant light supports the hypothesis of Haldar (1996) that a detectable amount of plasma melatonin is always present in pinealectomized palm squirrels. Sources of melatonin other than the pineal gland have been suggested, such as the retina (Gern and Ralph, 1979) and the Harderian gland (Olcese and Wesche, 1989), and these may have contributed to the plasma melatonin detected in female palm squirrels kept under constant light in the present study. However, prolonged exposure to constant darkness (that is, about 75 days) may have led the squirrels to enter into a refractory period, during which the rhythmic secretion of melatonin from the pineal gland becomes disturbed and finally insensitive to different photoperiodic conditions, resulting in a comparatively low concentration of plasma melatonin. Constant dark exposure for about 75 days may have exhausted the melatonin-secreting cells of the pineal gland and decreased pineal gland activity, resulting in the reduced pineal gland mass, pineal protein content and the low plasma melatonin concentration.

Constant light reduced oestradiol synthesis and release owing to the hypoactive pineal gland. In females kept under constant darkness, pineal gland activity was lower but plasma oestradiol concentrations were greater because the 
decrease in pineal gland activity hastened postpartum recovery. The increased plasma oestradiol concentrations prepared the females for the next mating and further implantation of embryos. The significant greater plasma progesterone concentrations in females kept under constant darkness supports the idea of faster postpartum recovery in these animals, while the significantly lower plasma progesterone concentrations in females exposed to short daylength delayed postpartum recovery. No detectable amounts of oestradiol or progesterone were found in the plasma of ovariectomized females.

In conclusion, during gestation and lactation, constant light, long daylength and short daylength conditions did not significantly effect pineal gland activity. However, constant darkness affected pineal gland activity negatively and advanced postpartum recovery.

The authors thank the University Grant Commission, New Delhi for financial support.

\section{References}

Attanasio A, Borelli P and Gupta D (1985) Circadian rhythms in serum melatonin from infancy to adolescence Journal of Clinical Endocrinology and Metabolism 61 388-389

Binkley S (1988) The Pineal: Endocrine and Neurocrine Function p. 304 Prentice Hall, New Jersey

Bishnupuri KS (1999) Maternal Pineal Physiology and Fetal Development in Indian Palm Squirrel, Funambulus pennanti. PhD Thesis, Banaras Hindu University

Bishnupuri KS and Haldar C (1999) Maternal photoperiodic exposures alter the neonatal growth, pineal functions and sexual development of the Indian palm squirrel, Funambulkus pennanti. Journal of Neural Transmission 106 869-881

Bowers CW and Zigmond RE (1982) The influence of the frequency and pattern of sympathetic nerve activity on serotonin- $N$-acetyltransferase in the rat pineal gland Journal of Endocrinology 330 279-296

Cardinali DP and Vacas MI (1984) Pineal gland, photoperiodic responses and puberty Journal of Endocrinological Investigation 7157

Carter DS and Goldman BD (1983) Antigonadal effect of timed melatonin infusion in pinealectomized Djungarian hamsters (Phodopus sungorus sungorus): duration is the critical parameter Endocrinology 113 1261-1267

Davis FC (1997) Melatonin: role in development Journal of Biological Rhythms 12 498-508

Elliot JA (1976) Circadian rhythm and photoperiodic time measurement in mammals Federal Proceeding 352339

Forsberg M and Madej A (1990) Effects of melatonin implants on plasma concentrations of testosterone, thyroxine and prolactin in the male silver fox (Vulpes vulpes) Journal of Reproduction and Fertility 89 351-358

Gern WA and Ralph CL (1979) Melatonin synthesis by retina Science 204 183-184
Haldar C (1996) Patterns of the plasma melatonin in the Indian palm squirrel (Funambulus pennanti). In Pineal Gland: Its Molecular Signals; Recent Researches in Biology 195-117 Ed. C Haldar, New Delhi

Haldar C and Singh S (1995) Modulation of ovarian function by various indoleamines during the sexually active phase in Indian palm squirrel, Funambulus pennanti. Canadian Journal of Zoology 73 266-269

Horton TH (1984) Growth and reproductive development in Microtus montanus is affected by prenatal photoperiod Biology of Reproduction 31 499-504

Horton TH, Ray SL and Stetson SM (1989) Maternal transfer of photoperiodic information in Siberian hamsters: melatonin injection program postnatal reproductive development expressed in constant light Biology of Reproduction 4134-39

Horton TH, Stachecki SA and Stetson MH (1990) Maternal transfer of photoperiodic information in Siberian hamsters: peripubertal reproductive development in the absence of maternal photoperiodic signals during gestation Biology of Reproduction 42 441-449

Innes DGL and Millar JS (1981) Body weights, litter size and energetics of reproduction in Clethriomys gapperi and Microtus pennsylvanicus. Canadian Journal of Zoology 59 785-789

Lowry OH, Rosenbrough NJ, Farr AL and Randall RJ (1951) Protein measurements with the folin-phenol reagent Journal of Biological Chemistry 193 265-275

Murphy BD, DiGregorio GB, Douglas DA and Gonzalez-Reyna A (1990) Interactions between melatonin and prolactin during gestation in mink (Mustela vison) Journal of Reproduction and Fertility 89 423-429

Nowak R, Elmhirst RN and Rodway RG (1985) A note on the effect of melatonin feeding on the initiation of ovarian activity and on plasma prolactin levels in lactating and non-lactating red deer hinds Animal Production 40 515-518

Olcese J and Wesche A (1989) The Harderian gland Comparative Biochemistry and Physiology 93A 655-665

Reiter RJ (1978) Interaction of photoperiod, pineal and seasonal reproduction as exemplified by findings in the hamster. In The Pineal and Reproduction $\mathrm{p}$. 169 Ed. RJ Reiter. Karger, Basel

Reiter RJ (1984) Pineal indoles: production, secretion and actions. In Neuroendocrine Perspectives 3 pp 345-377 Eds EE Muller and RM Macleod. Elsevier Science Publishers, Amsterdam

Reiter RJ (1986) Pineal melatonin production: photoperiodic and hormonal influences. In Advances in Pineal Research 177-87 Eds RJ Reiter and M Karasek. John Libbey, London

Reiter RJ (1991) Pineal metabolism: cell biology of its synthesis and its physiological interactions Endocrine Reviews 12 151-191

Rollag MD and Niswender GD (1976) Radioimmunoassay of serum concentrations of melatonin in sheep exposed to different light regimes Endocrinology 98 482-488

Stadman TC (1957) Preparation and assay of cholesterol and ergosterol. In Methods in Enzymology pp 392-394 Eds PC Sidney and OK Nathan. Academic Press, New York

Stetson MH and Tate-Ostrff B (1981) Hormonal regulation of the annual reproductive cycle of Golden hamster General Comparative Endocrinology 329 960

Stetson MH, Elliott JA and Goldman BD (1986) Maternal transfer of photoperiodic information influences the photoperiodic response of prepubertal Djungarian hamsters (Phodopus sungorus sungorus) Biology of Reproduction 34 664-669

Tamarkin L, Baird CJ and Almeida OFX (1985) Melatonin: a coordinating signal for mammalian reproduction? Science 227 714-720 